\title{
CARACTERIZAÇÃO SENSORIAL E REOLÓGICA DE SOBREMESAS DE SOJA ENRIQUECIDAS COM POLPA DE GOIABA
}

\author{
Jordana Corralo Spada ${ }^{1}$ \\ Aline Schwertner Palma ${ }^{2}$ \\ Analú Barbosa da Silva ${ }^{2}$ \\ Josete Baialardi Silveira ${ }^{2}$ \\ Mariana Lenzi Nodari² \\ Roberta Capalonga ${ }^{2}$ \\ Sabrina Bartz ${ }^{2}$ \\ Simone Hickmann Flôres ${ }^{3}$ \\ Ligia Damasceno Ferreira Marczak ${ }^{4}$ \\ Isabel Cristina Tessaro ${ }^{4}$ \\ Nilo Sérgio Medeiros Cardozo 4
}

\begin{abstract}
Os alimentos funcionais vêm sendo bastante estudados devido aos benefícios para a saúde e prevenção de doenças. Assim, a produção de alimentos utilizando ingredientes com características funcionais, como a soja, tem sido de grande interesse para suprir as necessidades da população. O presente estudo objetivou caracterizar sensorialmente sobremesas de soja sabor goiaba com aporte proteico pela adição de proteína isolada e extrato de soja. Realizouse a Análise Descritiva Quantitativa (ADQ) com dez provadores treinados para avaliar os seguintes atributos: cor rosa, consistência, sabor goiaba, sabor soja e cremosidade. A amostra padrão (com apenas extrato de soja) apresentou médias estatisticamente iguais quando comparada a amostra com proteína isolada de soja em todos atributos avaliados. Assim, é possível produzir um alimento com maior aporte proteico sem ocasionar mudanças sensoriais ao produto, visto que a substituição do extrato pela proteína isolada de soja na sobremesa não proporcionou mudanças perceptíveis pelos provadores. As sobremesas tiveram indíces de aceitação superior a $70 \%$ e não obtiveram diferença estatística em nenhum atributo. Ambas as amostras apresentaram comportamento pseudoplástico, porém a amostra com isolado de soja apresentou maior viscosidade e maior pseudoplasticidade.
\end{abstract}

PALAVRAS CHAVE: ALIMENTO COM SOJA; ANÁLISE SENSORIAL; ANÁLISE DESCRITIVA QUANTITATIVA; TESTE AFETIVO.

${ }^{1}$ Aluna do Curso de Pós-graduação do Departamento de Engenharia Química, Universidade Federal do Rio Grande do Sul (UFGRS), Porto Alegre, RS- Brasil (email:jcs@enq.ufrgs.br).

${ }^{2}$ Alunos do Curso de Pós-graduação do Instituto de Ciência e Tecnologia de Alimentos, Universidade Federal do Rio Grande do Sul (UFGRS), Porto Alegre, RS- Brasil (robertacapalonga@yahoo.com.br)

${ }^{3}$ Professora Doutora do Instituto de Ciência e Tecnologia de Alimentos, Universidade Federal do Rio Grande do Sul (UFGRS), Porto Alegre, RS- Brasil (email:simoneflores@ufrgs.br).

4 Professores Doutores do Departamento de Engenharia Química, Universidade Federal do Rio Grande do Sul (UFGRS), Porto Alegre, RS- Brasil (email:nilo@enq.ufrgs.br). 


\section{INTRODUÇÃO}

A preocupação da população em relação à alimentação vem mudando muito nas últimas décadas. Até pouco tempo atrás, o alimento era considerado apenas fonte de nutrientes essenciais à manutenção da vida. Atualmente, é objeto de estudos que buscam relacioná-lo à prevenção de doenças e melhoria das funções de órgãos e tecidos. Existem inúmeras pesquisas em relação a alimentos funcionais e as descobertas das funcionalidades de alguns de seus componentes ativos que são capazes de reduzir o risco de doenças (SALGADO, 2001). Dentre os alimentos cujas alegações de saúde têm sido amplamente divulgadas pela mídia, destaca-se a soja (BEHRENS \& DA SILVA, 2000). Resultados de estudos indicam que populações que consomem mais a soja, um grão rico em fibras e que pode substituir a carne em alguns casos, têm menor incidência de câncer de cólon, mama e próstata, além da prevenção de disfunções como hipertensão, hipercolesterolemia e osteoporose (HE et al., 2005; ZHUO et al., 2004; MESSINA, 2003; SALGADO, 2001).

O Brasil é o segundo produtor mundial de soja e seu complexo agroindustrial movimenta anualmente cerca de US $\$ 50$ bilhões. Porém, o consumo humano dessa leguminosa e de seus derivados é ainda restrito no país em razão de aspectos socioculturais e hábitos alimentares da população, fato que estimula a pesquisa e o desenvolvimento de produtos mais atrativos ao consumidor (TORREZAN et al., 2004).

A soja, considerada alimento funcional, fornece nutrientes ao organismo e diversos benefícios para a saúde, devido principalmente ao alto teor e qualidade proteica (MONTEIRO et al., 2004). Contém lipídios com alta concentração de ácidos graxos polinsaturados, teores consideráveis de vitaminas do complexo $\mathrm{B}$, fibras alimentares, oligossacarídeos com potencial prebiótico, como rafinose e estaquiose, vitaminas e minerais (FUCHS, 2005).

A funcionalidade da proteína de soja foi reconhecida em 1999 pelo FDA, órgão de controle de alimentos dos Estados Unidos da América. A Associação Americana do Coração recomenda o consumo de alimentos com soja para pacientes com elevados níveis de colesterol. Em programas federais de alimentação escolar foi comprovado que a soja pode substituir, sem prejuízo, a proteína animal até o nível de 30\% (MESSINA et al., 2002). Segundo WILCOX (1985), com porcentagem de proteína de $40 \%$, aproximadamente, a soja apresenta grande interesse para a alimentação como substituto da carne. Ela está presente nas dietas vegetarianas, consideradas mais saudáveis, já que os vegetarianos apresentam menor incidência de problemas cardiovasculares (FRIEDMAN \& BRANDON, 2001).

Entre os derivados da soja mais utilizados, destacam-se o extrato de soja e a proteína isolada, sendo que a proteína isolada apresenta maior conteúdo proteico ( $>98 \%)$ quando comparada ao extrato de soja (44\%), além de menor porcentagem de gordura. Apesar de ambas as matériasprimas serem fáceis de manipular e apresentarem baixo sabor residual, a incorporação da proteína isolada em produtos ácidos mostra-se mais complicada, devido a sua maior tendência à precipitação proteica. Com isso, o produto final pode apresentar diferenças sensoriais, como alterações na cremosidade, presença de maior sabor residual.

Uma possível barreira para a aceitação do consumidor é a percepção negativa do sabor da soja pelos consumidores. Lanches rotulados como contendo $10 \mathrm{~g}$ de proteína de soja foram classificados como tendo sabor e sabor residual desfavorável, mesmo quando a soja não estava presente nos produtos (WANSINK, 2003). O benefício da soja para a saúde poderia desempenhar um papel na seleção de alimentos. A rotulagem de alimentos que enfatizou conteúdo de soja, fazendo alegações em relação à saúde, foi influenciada negativamente em detrimento da percepção e especialmente no gosto dos consumidores (WANSINK \& PARK 2002). Desta forma, torna-se necessário a utilização de ingredientes que promovam um mascaramento do sabor da soja nos alimentos para que ocorra a aceitação dos mesmos pelos consumidores.

Entre os métodos sensoriais analíticos utilizados em alimentos, destaca-se a Análise Descritiva Quantitativa (ADQ) que proporciona uma completa descrição das propriedades sensoriais 
de um produto, representando um dos métodos mais completos e sofisticados para a caracterização sensorial de atributos importantes (STONE \& SIDEL, 2004).

As vantagens da $A D Q$ sobre os outros métodos de avaliação consistem na confiança no julgamento de uma equipe composta por julgadores treinados, no desenvolvimento de uma linguagem descritiva objetiva, mais próxima à linguagem do consumidor, no desenvolvimento consensual da terminologia descritiva a ser utilizada (BEHRENS \& DA SILVA, 2000).

O presente trabalho teve como objetivo avaliar reologicamente e sensorialmente, através de Análise Descritiva Quantitativa (ADQ) e aceitação, duas sobremesas (sabor goiaba) elaboradas com extrato e proteína isolada de soja.

\section{MATERIAIS E MÉTODOS}

\subsection{MATÉRIAS-PRIMAS}

O extrato de soja e a proteína isolada de soja foram fornecidos gratuitamente pela Olvebra (Eldorado do Sul, RS, Brasil) e pela Marsul (Montenegro, RS, Brasil), respectivamente. As gomas carboximetilcelulose (CMC) e carragena foram doadas pelas empresas Hexus Food (Portão, RS, Brasil) e Cargill Alimentos (Minnesota, Estados Unidos), respectivamente. A polidextrose foi cedida pela Danisco Brasil Ltda. (São Paulo, Brasil). A polpa de fruta foi adquirida da empresa Mais Fruta (Antônio Prado, RS, Brasil) e o amido modificado foi fornecido pela Corn Products (Brasil Ingredientes Industriais, Mogi-Guaçu, Brasil). A formulação das sobremesas está descrita na Tabela 1.

As duas amostras de sobremesa de soja sabor goiaba foram preparadas no Laboratório de Tecnologia e Processamento de Alimentos, do Departamento de Engenharia Química, da Universidade Federal do Rio Grande do Sul (UFRGS) em Porto Alegre-RS, em condições idênticas.

TABELA 1. INGREDIENTES (G/100 G) EMPREGADOS NO DESENVOLVIMENTO DAS SOBREMESAS A BASE DE SOJA.

\begin{tabular}{ccc}
\hline Ingredientes & $\begin{array}{c}\text { Formulação Padrão } \\
(\mathbf{g} / \mathbf{1 0 0 g})\end{array}$ & $\begin{array}{c}\text { Formulação com } \\
\text { proteína soja } \\
(\mathbf{g} / \mathbf{1 0 0 g})\end{array}$ \\
\hline Sacarose & 9 & 9 \\
Polpa de goiaba & 13 & 13 \\
Extrato hidrossolúvel de soja & 5 & 2,5 \\
Proteína isolada de soja & --- & 2,5 \\
Amido modificado & 3,3 & 3,3 \\
Polidextrose & 2 & 2 \\
Suco de goiaba em pó & 1,5 & 1,5 \\
Carragena & 0,3 & 0,3 \\
CMC & 0,4 & 0,4 \\
Água & qs $100 \mathrm{~g}$ & qs $100 \mathrm{~g}$ \\
\hline
\end{tabular}

qs = quantum sufficit para $100 \mathrm{~g}$. 


\subsection{ANÁLISE DESCRITIVA QUANTITATIVA (ADQ)}

Os membros da equipe foram recrutados entre alunos, funcionários e professores do Instituto de Ciência e Tecnologia de Alimentos (ICTA), da UFRGS, sendo a participação voluntária. A ADQ foi realizada de acordo com STONE \& SIDEL (2004). O recrutamento dos provadores foi realizado aplicando-se 20 questionários. A pré-seleção dos provadores foi realizada com a aplicação do teste de reconhecimento básico de sabores (doce, salgado, ácido, amargo) e de quatro testes triangulares.

O desenvolvimento da terminologia descritiva dos produtos foi elaborado utilizandose o Método de Rede, descrito por Kelly e citado por MOSKOWITZ (1983). Os produtos foram apresentados aos pares, em cabines individuais de avaliação sensorial, aos provadores previamente selecionados. Os indivíduos foram solicitados a descrever as similaridades e as diferenças entre as amostras de cada par com relação à aparência, aroma, sabor e textura. Dois pares de amostras foram analisados por sessão. Após o término das sessões, uma discussão em grupo foi conduzida sob a supervisão de um líder com o objetivo de agrupar termos descritivos semelhantes e gerar amostras referências através de consenso, e a partir desses resultados foi elaborada a ficha de avaliação das amostras. A definição de cada termo descritivo foi desenvolvida pela equipe sensorial e está apresentada na Tabela 2. Os materiais de referência e a definição de cada termo descritivo foram colocados à disposição dos provadores, em cada sessão, durante o período de treinamento.

\section{TABELA 2. DEFINIÇÃO DOS TERMOS DESCRITIVOS E REFERÊNCIAS UTILIZADAS COMO EXTREMOS DE ESCALA DE INTENSIDADE NA ANÁLISE DESCRITIVA QUANTITATIVA (ADQ) DAS SOBREMESAS A BASE DE SOJA PARA OS ATRIBUTOS DE APARÊNCIA, SABOR E TEXTURA.}

\begin{tabular}{|c|c|c|}
\hline Termo descritor (atributo) & Definição & Referência \\
\hline & Aparência & \\
\hline \multirow[t]{2}{*}{ a. Cor rosa } & \multirow[t]{2}{*}{ Intensidade da cor rosa } & $\begin{array}{l}\text { Fraca: leite com corante } \\
\text { (proporção: 100:1) }\end{array}$ \\
\hline & & Intensa: sobremesa (F1) \\
\hline \multirow[t]{2}{*}{ b. Consistência } & \multirow{2}{*}{$\begin{array}{l}\text { Resistência ao escorrer da } \\
\text { colher }\end{array}$} & $\begin{array}{c}\text { Fluida: leite com corante } \\
\text { (proporção: 100:1) }\end{array}$ \\
\hline & & Firme: branquinho (Moça) \\
\hline & Sabor & \\
\hline \multirow{3}{*}{ a. Goiaba } & & Ausente: mingau (F2) \\
\hline & $\begin{array}{l}\text { Intensidade do sabor } \\
\text { característico de goiaba }\end{array}$ & $\begin{array}{l}\text { Intenso: Polpa com } \\
\text { açúcar e suco em pó } \\
\text { (proporção: 100:5:1,5) }\end{array}$ \\
\hline & \multirow[b]{2}{*}{ Intensidade do sabor de soja } & Ausente: mingau (F2) \\
\hline b. Soja & & Intenso: F3 \\
\hline
\end{tabular}

\section{Textura}

a. Cremosidade

Percepção de consistência

Fraco: leite com corante

macia na boca

(proporção: 100:1)

Forte: doce de leite

\footnotetext{
* F1: formulação padrão sem polpa de fruta e com $20 \mathrm{~g}$ de suco de goiaba em pó (g/100 g).

F2: $86,2 \mathrm{ml}$ de leite semidesnatado; $5,2 \mathrm{~g}$ de amido de milho comercial; $8,6 \mathrm{~g}$ de açúcar (g/100 g).

F3: $87,8 \mathrm{~g}$ de água; $8,7 \mathrm{~g}$ de extrato de soja; $3,5 \mathrm{~g}$ de proteína isolada de soja ( $\mathrm{g} / 100 \mathrm{~g}$ ).
} 
A equipe definitiva para a $A D Q$ foi selecionada com base no poder de discriminação entre amostras, repetibilidade e concordância entre os julgadores, verificada através de análise de variância de dois fatores (amostra e repetição) para cada provador em relação a cada atributo. Os atributos que não foram bem discriminados pela equipe de provadores, devido à falta de consenso, foram eliminados. A equipe treinada, mediante termo de consentimento livre e esclarecido, avaliou o perfil sensorial das duas amostras de sobremesa de soja sabor goiaba. A intensidade de cada descritor foi avaliada em cada amostra pela escala não estruturada de nove centímetros, com termos de intensidade ancorados em seus extremos, sendo o mínimo à esquerda e o máximo à direita. Os provadores receberam as amostras refrigeradas $(30 \mathrm{~g})$ em copos plásticos descartáveis codificados com números de três dígitos aleatórios, acompanhados de copos de água em temperatura ambiente.

Os testes foram realizados em cabines individuais no Laboratório de Análise Sensorial do Instituto de Ciência e Tecnologia de Alimentos, da Universidade Federal do Rio Grande do Sul. Todos os provadores receberam e assinaram o Termo de consentimento esclarecido aprovado pelo Comitê de ética da UFRGS (protocolo Número 91.497).

\subsection{ACEITAÇÃO SENSORIAL}

Para avaliar a aceitação das amostras, os atributos cor, aparência, consistência, aroma, sabor, cremosidade e aceitação global foram avaliados através de uma escala hedônica de nove pontos estruturados, variando de 1 = 'Desgostei muitíssimo' a 9 = 'Gostei muitíssimo' (ABNT, 1993). As amostras resfriadas $\left(7^{\circ} \mathrm{C}\right)$ foram servidas, em ordem aleatória, em copos plásticos com colheres. Água mineral foi disponibilizada para limpeza do palato entre as amostras. Os testes foram efetuados em cabines individuais, com luz branca e temperatura de $25^{\circ} \mathrm{C}$, entre $10-12 \mathrm{~h}$ e $14-17 \mathrm{~h}$. O índice de aprovação (\%) de cada amostra foi calculado como segue:

Índice de aprovação $(\%)=\frac{\bar{M}}{9} \cdot 100 \%$

onde, $\bar{M}$ é o escore médio que a amostra recebeu nos testes afetivos e 9 representa o tamanho da escala hedônica.

\subsection{ANÁLISE REOLÓGICA}

As análises reológicas foram realizadas em reômetro rotacional (Ares, TA Instruments, New Castle, USA), utilizando a geometria placa-placa e abertura (gap) de 1,5 mm. O controle da temperatura foi realizado através de ar circulante. As curvas de escoamento das amostras foram determinadas a $25^{\circ} \mathrm{C}$ e a taxa de cisalhamento variou de 0 a $200 \mathrm{~s}^{-1}$. Os ensaios foram realizados em duplicata e os dados experimentais foram ajustados de acordo com o modelo reológico de Ostwald-de-Waelle (Lei da Potência, Equação 2):

$$
\tau=K \dot{\gamma}^{n}
$$

onde, $\tau$, tensão de cisalhamento $\left(\mathrm{N} \cdot \mathrm{m}^{-2}\right.$ ou $\left.\mathrm{Pa}\right) ; \gamma$, taxa de cisalhamento $\left(\mathrm{s}^{-1}\right) ; K$, índice de consistência (Pa.s) e $n$, índice de fluxo (adimensional). A estimação dos parâmetros do modelo foi realizada utilizando o software Statistica versão 10.0 (Statsoft Inc., Tulsa, Estados Unidos)

\subsection{ANÁLISE ESTATÍSTICA}

Para cada atributo foi calculada a média e o desvio padrão, e os resultados da ADQ foram submetidos à Análise de Variância (ANOVA) $(p<0,05)$ e teste de Tukey, utilizando o software Statistica 11.0. 


\section{RESULTADOS E DISCUSSÃO}

\subsection{ANÁLISE DESCRITIVA QUANTITATIVA}

Após a aplicação dos 20 questionários, 15 provadores participaram da fase de treinamento. Sendo que destes, somente 10 foram considerados treinados. Os dez provadores que compuseram a equipe são na maioria do sexo feminino ( $75 \%)$.

Os atributos obtidos pelo Método de Rede para a ADQ foram: cor rosa, consistência aparente, sabor de soja, sabor goiaba e cremosidade. A Tabela 3 apresenta a média e o desvio padrão de cada atributo avaliado por amostra.

\section{TABELA 3. RESULTADOS DAS MÉDIAS E DESVIO PADRÃO DOS ATRIBUTOS SENSORIAIS QUE CARACTERIZARAM AS AMOSTRAS NA ADQ.}

\begin{tabular}{ccc} 
ATRIBUTO & $\begin{array}{c}\text { Amostra Padrão } \\
\text { Média } \pm \text { DP* }\end{array}$ & $\begin{array}{c}\text { Amostra com proteína } \\
\text { isolada de soja } \\
\text { Média } \pm \text { DP* }\end{array}$ \\
\hline Cor Rosa & $3,17^{\mathrm{a}} \pm 1,59$ & $3,20^{\mathrm{a}} \pm 1,48$ \\
Consistência & $5,78^{\mathrm{a}} \pm 0,85$ & $5,90^{\mathrm{a}} \pm 1,33$ \\
Sabor Goiaba & $4,87^{\mathrm{a}} \pm 2,32$ & $5,75^{\mathrm{a}} \pm 1,83$ \\
Sabor Soja & $1,95^{\mathrm{a}} \pm 2,43$ & $1,75^{\mathrm{a}} \pm 2,32$ \\
Cremosidade (textura) & $5,65^{\mathrm{a}} \pm 1,41$ & $6,20^{\mathrm{a}} \pm 1,42$ \\
\hline
\end{tabular}

${ }^{*} \mathrm{DP}=$ Desvio Padrão

Letras iguais na mesma linha indicam que não há diferença estatística ao nível de $5 \%$.

Pode-se constatar que a amostra feita somente com extrato de soja apresentou médias estatisticamente iguais $(p>0,05)$ quando comparada à amostra com proteína isolada de soja, ou seja, nenhum atributo avaliado apresentou diferenças sensoriais perceptíveis pela equipe na comparação das duas amostras.

SANTANA et al (2006), ao avaliarem amostras de iogurte light sabor pêssego com e sem adição de proteína de soja, observaram que a amostra adicionada de proteína de soja apresentou diferença significativa no atributo sabor pêssego quando comparada às amostras sem adição de proteína de soja. Já no presente estudo, os resultados encontrados demonstraram que não houve diferença significativa para o atributo sabor de goiaba.

Pode-se observar que a adição de proteína isolada de soja não afetou na percepção do sabor de soja das sobremesas já que em ambas a intensidade deste atributo avaliado pelos julgadores foi baixa.

Ao contrário de TÁRREGA \& COSTELL (2007), que detectaram diferenças significativas na cremosidade de sobremesas lácteas sabor baunilha com diferentes espessantes (amido, carragena, goma guar, goma xantana etc.) e quantidade dos mesmos, neste trabalho não foram encontradas diferenças nesse atributo ao substituir o extrato pela proteína isolada na proporção de $50 \%$. Tal atributo poderia ser diferenciado se houvesse uma substituição total ou parcial de maior porcentagem do extrato pela proteína, visto que a mesma tem maior poder de retenção de água, que confere maior viscosidade ao produto.

Ao avaliarem o perfil sensorial de alimento com soja sabor laranja, TORREZAN et al. (2004) demonstraram que existiu diferença na cor entre as amostras A (alimento com soja sabor laranja com adição de açúcar) e B (alimento com soja sabor laranja light), sendo ambas da mesma marca, 
sendo que a amostra A apresentou cor um pouco mais marcante em relação as demais. Quanto ao presente estudo, constatou-se que não houve diferença estatística na cor rosa entre as amostras, ao substituir parcialmente o extrato pela proteína isolada.

\subsection{TESTE DE ACEITAÇÃO SENSORIAL}

A Tabela 4 apresenta as médias dos atributos sensoriais encontrados no teste de aceitação das sobremesas. Os resultados revelaram que a amostra padrão não diferiu significativamente da amostra com proteína isolada de soja (PIS) em relação a nenhum dos atributos avaliados. Todos os atributos receberam médias superiores a 6 (gostei levemente). As médias referentes à aceitação global da amostra padrão e da amostra com PIS foram 6,7 e 6,5, respectivamente, ou seja, elas obtiveram boa aceitação sensorial. Com esses valores calculou-se o índice de aceitação (Eq.1) para ambas as amostras (74\% para a amostra padrão e $72 \%$ para a amostra com PIS).

Cabe ressaltar que esses resultados corroboram com aqueles encontrados na $A D Q$, visto que os provadores também não detectaram diferenças significativas entre as amostras.

\section{TABELA 4. RESULTADOS DAS MÉDIAS E DESVIO PADRÃO DOS ATRIBUTOS SENSORIAIS QUE CARACTERIZARAM AS AMOSTRAS NOS TESTES DE ACEITAÇÃO SENSORIAL (AFETIVOS).}

\begin{tabular}{lcc}
\hline ATRIBUTO & $\begin{array}{c}\text { Amostra Padrão } \\
\text { Média } \pm \text { DP* }\end{array}$ & $\begin{array}{c}\text { Amostra com proteína } \\
\text { isolada de soja } \\
\text { Média } \pm \mathbf{D P}\end{array}$ \\
\hline Aparência & $6,02^{\mathrm{a}} \pm 1,68$ & $6,00^{\mathrm{a}} \pm 1,67$ \\
Cor & $6,07^{\mathrm{a}} \pm 1,86$ & $6,04^{\mathrm{a}} \pm 1,82$ \\
Aroma & $6,51^{\mathrm{a}} \pm 1,41$ & $6,80^{\mathrm{a}} \pm 1,32$ \\
Consistência & $6,79^{\mathrm{a}} \pm 1,36$ & $6,73^{\mathrm{a}} \pm 1,74$ \\
Cremosidade & $7,22^{\mathrm{a}} \pm 1,29$ & $6,95^{\mathrm{a}} \pm 1,46$ \\
Sabor & $6,79^{\mathrm{a}} \pm 1,28$ & $6,66^{\mathrm{a}} \pm 1,43$ \\
Aceitação global & $6,72^{\mathrm{a}} \pm 1,37$ & $6,52^{\mathrm{a}} \pm 1,52$ \\
\hline
\end{tabular}

${ }^{*} \mathrm{DP}=$ Desvio Padrão

Letras iguais na mesma linha indicam que não há diferença estatística ao nível de 5\%.

Outros trabalhos com sobremesas a base de soja também obtiveram boa aceitação sensorial com índices de aceitação superiores a 70\% (SOLER, 2005; CAMIRE, DOUGHERTY \& TEH, 2006; TOMIKAWA, 2009; GRANATO et al., 2010; GRANATO, MASSON \& RIBEIRO, 2012) .

TEH, DOUGHERTY \& CAMIRE (2005) avaliaram a aceitação de sobremesas congeladas contendo proteína isolada de soja e suco de mirtilo em diferentes concentrações, com escala hedônica de 9 pontos. Os escores variaram de 7,1 - 7,5 para a cor, 5,2 - 6,4 para o flavor e 4,4 - 6,9 para a cremosidade.

SOLER (2005) também encontrou escores acima de 5 em escala de 9 pontos, para os atributos referentes à aparência, cor, flavor, textura e aceitação global ao avaliar sobremesas congeladas com proteína de soja e leite de coco com diferentes sabores: baunilha, cheesecake de morango e pêssego. A amostra com sabor cheesecake de morango apresentou os maiores escores (acima de 7) para os atributos supracitados.

GRANATO, MASSON \& RIBEIRO (2012) desenvolveram sobremesas aeradas com diferentes quantidades de proteína de soja $(2-3 \%)$ e suco de maracujá ( $25-35 \%)$ através 
de um planejamento fatorial $2^{2}$. Nesse estudo, os testes de aceitação sensorial foram feitos com escala hedônica de 7 pontos. Apenas as sobremesas elaboradas com $2 \%$ de proteína de soja apresentaram escores menores que 5 (gostei levemente) para os atributos sabor e cremosidade. A amostra com menor quantidade de suco (25 \%) e proteína de soja (2 \%) foi a única que apresentou escores inferiores a 5 para os atributos cor e aceitação global.

GRANATO et al. (2010) também utilizaram goiaba na formulação de sobremesas aeradas com soja. Nesse trabalho, os autores variaram o conteúdo de suco de goiaba (22-32\%) e proteína de soja ( 1 a $3 \%$ ) através de um planejamento fatorial composto central $2^{2}$. Uma escala hedônica de 7 pontos foi utilizada para ranquear os atributos sensoriais (aceitação, cor e cremosidade). As amostras apresentaram escores médios entre 4 (indiferente) e 6 (gostei moderadamente) para os atributos avaliados. Somente a amostra com $22 \%$ de suco e $2 \%$ de proteína de soja foi considerada inaceitável (escore 4,35). Por outro lado, a amostra com maior porcentagem de soja (3\%) e $27 \%$ de suco apresentou o valor médio mais elevado para a aceitação $(6,00)$.

\subsection{ANÁLISE REOLÓGICA}

Ambas as amostras apresentaram comportamento não newtoniano pseudoplástico, onde a viscosidade dinâmica decresce com o aumento da taxa de cisalhamento. Os dados encontrados nas curvas de fluxo se ajustaram bem ao modelo de Ostwald-de-Waelle, visto que os valores dos coeficientes de correlação $\left(R^{2}\right)$ foram 0,993 e 0,989 para as amostras padrão e com PIS, respectivamente. A amostra contendo proteína isolada de soja (Eq.4) apresentou menor caráter pseudoplástico, visto que o valor de $\mathrm{n}$ (índice de fluxo) foi superior. O coeficiente de consistência $(K)$, que também diferiu de forma significativa entre as amostras, foi superior nas amostras contendo apenas o extrato hidrossolúvel de soja. Com esses parâmetros, é possível calcular a viscosidade desses produtos, visto que ela é um importante parâmetro de controle de qualidade durante um processo industrial. Com isso, pode-se afirmar que a amostra sem proteína isolada de soja apresentou maior viscosidade, e conforme comentado anteriormente, devido à sua maior pseudoplasticidade, ela está mais sujeita a mudanças de viscosidade durante sua produção.

$$
\tau_{\mathrm{A}}=(54,7 \pm 1,3) \gamma^{(0,29 \pm 0,03)}
$$

(4)

$$
\tau_{\mathrm{B}}=(29,3 \pm 1,1) \gamma^{(0,42 \pm 0,02)}
$$

Os dados reológicos das curvas de fluxo de sobremesas lácteas (TÁRREGA E COSTELL, 2006; ARCIA, COSTELL \& TÁRREGA, 2010 e TÁRREGA \& COSTELL, 2007) e sobremesas com baixo teor de gordura, à base de amido de tapioca e k-carragena (GONZÁLEZ-TOMÁS et al. 2008) também foram adequados ao modelo de Ostwald-de-Waelle. Os valores de $K$ encontrados por esses autores variaram de 0,4 a 44 , mostrando uma ampla faixa de valores que pode ser encontrada para o índice de consistência. Já os resultados de $n$, variaram de 0,3 a 0,6, similar aos encontrados neste trabalho.

\section{CONCLUSÃO}

Com base nos resultados obtidos, pode-se concluir que, a partir da avaliação do perfil sensorial das sobremesas à base de soja sabor goiaba, a amostra padrão não apresentou diferença estatística quanto aos atributos avaliados. Sendo assim, a adição da proteína isolada de soja à sobremesa permitiu a obtenção de um produto com maior conteúdo proteico e menor percentual de gordura, sem modificação das características sensoriais relacionadas ao sabor, consistência, cor e textura podendo ser utilizada na elaboração das mesmas. Os resultados encontrados nos 
testes de aceitação corroboraram com a $A D Q$, visto que não foram detectadas diferenças entre as amostras quanto a nenhum atributo sensorial. A amostra preparada com isolado de soja apresentou maior viscosidade e maior pseudoplasticidade estando, dessa maneira, mais sujeita a modificações reológicas durante o processamento.

\section{ABSTRACT}

\section{SENSORY AND RHEOLOGICAL CHARACTERIZATION OF SOY BASED DESSERTS ENRICHED WITH GUAVA PULP}

Functional foods have been widely studied due to its benefits to health and disease prevention. Thus, the production of food using ingredients with functional features, such as soybeans, is of great interest to supply the needs of the population. The present study aimed to characterize desserts with guava pulp and soy by adding protein isolate and soy extract. Quantitative Descriptive Analysis (QDA) was performed with ten trained panelists to evaluate the following attributes: pink color, consistency, guava flavor, soy flavor and creaminess. According to the QDA, the sample with isolated soy protein was statistically equal to the standard sample (with soy extract) with relation to the considered sensory attributes. Thus, the addition of isolated soy protein in the dessert led to food with higher protein content without causing noticeable sensory changes in the product. The desserts had indices of acceptance higher than $70 \%$ and did not show statistical difference in any attribute. Both samples showed pseudoplastic behavior, but the sample with isolated soy showed higher viscosity and pseudoplasticity.

KEY-WORDS: SOY PRODUCT; SENSORY ANALYSIS; QUANTITATIVE DESCRIPTIVE ANALYSIS; CONSUMER TEST.

\section{REFERÊNCIAS}

1 ABNT- Associação Brasileira de Normas Técnicas. NBR 12806: Análise sensorial dos alimentos e bebidas terminologia. Rio de Janeiro, 1993.

2 ARCIA, P. L., COSTELL, E.; TÁRREGA, A. Thickness suitability of prebiotic dairy desserts: Relationship with rheological properties. Food Research International, v.43, n.10, p.2409-2416, 2010.

3 BEHRENS, J. H.; SILVA, M. A. A. P. Perfil sensorial de vinhos brancos varietais brasileiros através de análise descritiva quantitativa. Ciência e Tecnologia de Alimentos, v. 20, n. 1, p. 60-67, 2000.

4 CAMIRE, M. E., DOUGHERTY, M. P.;TEH, Y. H. Frozen wild blueberry-tofu-soymilk desserts. Journal of Food Science, V.71, n.2, Mar, p.S119-S123. 2006.

5 FAO. Food And Agriculture Organization. FAOSTAT DATABASE QUERY. Disponível em<http://faostat.fao.org/faostat/ form?collection=FS.CropsAndProducts\&Domain=FS\&servlet=1\&hasbulk=\&version=ext\&language=EN> . Acesso em: 20 dez. 2012.

6 FRIEDMAN, M.; BRANDON, D.L. Nutritional and health benefits of soy proteins. Journal of Agriculture and Food Chemistry, v. 49, n.3, p. 1069-1086, 2001.

7 FUCHS, R.H.B. "logurte" de soja suplementado com oligofrutose e inulina. Ciência e Tecnologia de Alimentos, v. 25, p. 175-181, 2005.

8 GONZÁLEZ-TOMÁS, L., BAYARRI, S., TAYLOR, A. J.; COSTELL, E. Rheology, flavour release and perception of low-fat dairy desserts. International Dairy Journal, v.18, n.8, p.858-866, 2008.

9 GRANATO, D., MASSON, M. L.; RIBEIRO, J. S. C. B. Sensory acceptability and physical stability evaluation of a prebiotic soy-based dessert developed with passion fruit juice. Ciência e Tecnologia de Alimentos, v.32, p.119-126. 2012.

10 GRANATO, D., RIBEIRO, J. C. B., CASTRO, I. A. E MASSON, M. L. Sensory evaluation and physicochemical optimisation of soy-based desserts using response surface methodology. Food Chemistry, v.121, n.3, p.899-906, 2010.

11 HE, J.; GU, D.; CHEN, W. X.; DUAN, X.; CHEN, J.; WHELTO, P. K. Effect of soybean protein on blood pressure: a randomized, controlled trial. Annals of Internal Medicine, v. 143, n. 1, p. 1-9, 2005. 
12 MESSINA M. Soyfoods and disease prevention: Part II - osteoporosis, breast cancer, and hot fl us. Agro Food Industry Hi-Tech. v. 14, n. 6, p.11-13, 2003.

13 MONTEIRO M.R.P; COSTA, N.M.B.; OLIVEIRA, M.G.A.; PIRES, C.V.; MOREIRA M.A. Qualidade protéica de linhagens de soja com ausência do Inibidor de Tripsina Kunitz e das isoenzimas Lipoxigenases. Revista de Nutrição, v. 17, p. 195-205, 2004.

14 MOSKOWITZ, H. R. Product Testing and Sensory Evaluation of Foods-Marketing and R\&D Approaches. Westport: Food and Nutrition Press, 605p., 1983.

15 NOTÍCIAS EMBRAPA SOJA. Evento revela panorama atual e perspectiva da soja no mundo. Disponível em: <http:// www.cnpso.embrapa.br/noticia/ver_noticia.php?cod_noticia=28>. Acesso em 05/12/2012.

16 PENHA, L.A.O.; FONSECA, I.C.B.; MANDARINO, J.M.; BENASSI, V.T. A soja como alimento: valor nutricional, benefícios para a saúde e cultivo orgânico. Boletim CEPPA, Curitiba, v. 25, n. 1, p. 91-102, 2007.

17 SALGADO, J. M.A. Importância dos alimentos funcionais. In: Salgado JMA, Alvarenga A, Lottemberg AMP, Borges VC. Impacto dos Alimentos Funcionais para a Saúde. Nutrição em Pauta, v. 48, p. 10-18, 2001.

18 SANTANA, L. R. R.; SANTOS, L. C. S.; NATALICIO, M. A.; MONDRAGON-BERNAL, O. L.; ELIAS, E. M.; SILVA, C. B.; ZEPKA, L. Q.; MARTINS, I. S. L.; VERNAZA, M. G.; CASTILLO-PIZARRO, C.; BOLINI, H. M. A. Perfil sensorial de iogurte light, sabor pêssego. Ciência e Tecnologia de Alimentos, v.26, n.3, p.619-625, 2006.

19 SOLER, L._Development of non-dairy frozen emulsion containing soy protein and coconut milk. Dissertação (Mestrado em Ciência de Alimentos). 2005. 84 f Departamento de Ciência de Alimentos, Louisiana State University and Agricultural and Mechanical College, Louisiana, 2005.

20 STONE, H., SIDEL, J. L. Descriptive analysis. Sensory evaluation practices. London: Academic Press, 2004, p.200-300.

21 TÁRREGA, A.; COSTELL, E. Effect of inulin addition on rheological and sensory properties of fat-free starch-based dairy desserts. International Dairy Journal, v.16, n.9, p.1104-1112, 2006.

22 TÁRREGA, A.; COSTELL, E. Colour and consistency of semi-solid dairy desserts: Instrumental and sensory measurements. Journal of Food Engineering, v.78, n.2, p.655-661, 2007.

23 TEH, Y. H., DOUGHERTY, M. P.; CAMIRE, M. E. Frozen blueberry-soy dessert quality. Journal of Food Science, v.70, n.2, p.119-122, 2005.

24 TOMIKAWA, M. M._Desenvolvimento de uma sobremesa a base de soja tipo petit suisse enriquecido com cálcio e alto teor proteico. 2009. 96 f. Dissertação (Mestrado em Engenharia de Alimentos) - Faculdade de Engenharia de Alimentos, Universidade Estadual de Campinas, Campinas, 2009.

25 TORREZAN, R. E. A. Avaliação do perfil sensorial de alimento com soja sabor laranja. Boletim CEPPA, v.22, n.2, 2004.

26 WANSINK, B. Overcoming the taste stigma of soy. Journal of Food Science, v. 68, n. 8, p. 2604-2606, 2003.

27 WANSINK, B.; PARK, S.B. Sensory suggestiveness and labeling: do soy label

28 bias taste? Journal of Sensory Studies, v. 17, n. 5, p.483-491, 2002.

29 WILCOX, J.R. Breeding soybeans for improved oil quantity and quality. In: WORLD SOYBEAN RESEARCH CONFERENCE, 3. Boulder, Colorado: Westview Press, 1985, p. 380-386.

30 ZHUO X.G.; MELBY, M.K.; WATANABE, S. Soy isofl avone intake lowers serum LDL cholesterol: a meta-analysis of 8 randomized controlled trials in humans. Journal of Nutrition, v.134, n. 9, p.2395-2400, 2004. 